\title{
The implant retained overdenture by Locator attachments on the edentulous mandible using Parallel guide $\mathrm{KIT}^{\circledR}$ : a case report
}

\author{
Hyeran Kim, Jun-Yup Kim, Hong-Seo Yang, Sang-Won Park*, Hyun-Pil Lim, Kwi-Dug Yun, Chan Park, \\ Jin-Ho Shin \\ Department of Prosthodontics, School of Dentistry, Chonnam National University, Gwangju, Republic of Korea
}

Overdenture using dental implants could improve the problems of conventional complete denture function which are pain during mastication, insufficient retention and stability. Locator attachment used widely for implant-retained overdenture has advantages that it needs the smallest vertical space and also its nylon male cap allows personalized retention for each case. However its retention force decreases rapidly with function rather than the bar and ball attachment. So, implant fixture should be positioned as parallel as possible. (J Dent Rehabil Appl Sci 2017;33(1):55-62)

Key words: Locator; attachment; implant-retained overdenture; parallel

\begin{abstract}
서론
상악 완전 무치악 환자에서는 전통적인 총의치가 가 장 추천되는 치료 방법인 것과는 달리 하악 무치악 환자 에서는 두 개의 임플란트를 이용한 임플란트 유지형 피 개의치가 첫 번째로 추천된다. ${ }^{1}$ 임플란트 피개의치를 위 해 사용되는 어태치먼트는 임플란트 사이의 연결 유무에 따라 크게 바(연결 고정형)와 개별유지장치(독립형)로 나 눌 수 있다. ${ }^{2,3}$ 개별유지장치에는 볼(ball), Locator, 자석 (magnet), 이중관형(telescopic crown) 등이 사용되고 있 다. ${ }^{4}$ 이 중 현재 널리 사용되는 어태치먼트인 Locator는 그간 국소의치나 피개의치에 널리 사용되어 왔던 ERA, O-ring, Cap형 어태치먼트의 조합으로, 자가배열(selfaligning), 이중유지(dual-retention), 유지력이 상실되 지 않으면서 10 도의 회전을 허용, 수직적으로 가장 작은 $3.17 \mathrm{~mm}$ 의 공간을 필요로 하는 특성을 지닌다. ${ }^{5}$ 또한,

제조사에서 다양한 유지력을 가지는 나일론 부품을 제 공하기 때문에 유지력 조절이 용이하다. 하지만 Locator 는 bar와 ball에 비해 기능하에서 유지력이 빠르게 감소 하는 특징을 가지고 있기 때문에 나일론 부품의 교체율 이 높은 편으로 가급적 임플란트를 평행하게 식립하려는 노력이 필요하다. ${ }^{6,7}$ 본 증례는 무치악 환자에서 하악에 2 개의 임플란트를 Parallel guide $\mathrm{KIT}^{\circledR}$ (Denture Guide, Osstem, Seoul, Korea)를 이용해 평행하게 심고, Locator 어태치먼트를 이용한 임플란트 피개의치로 수복하여 만 족할 만한 결과를 얻었다.

\section{증례보고}

본 증례의 환자는 74 세 여자 환자로 기존에 사용하던 상하악 국소의치가 파절되고, 지대치가 흔들려 의치를 다시 제작하고 싶다는 주소로 내원하였다(Fig. 1). 환자

Copyright@ 2017 The Korean Academy of Stomatognathic Function and Occlusion. (c) It is identical to Creative Commons Non-Commercial License. 

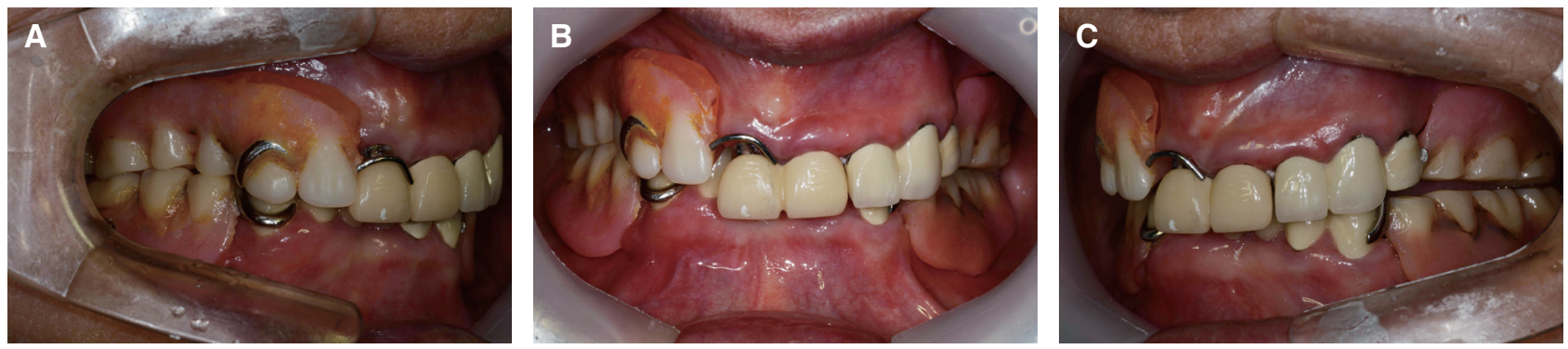

Fig. 1. Intraoral photo image at initial visit. (A) Right lateral view, (B) Frontal view, (C) Left lateral view.

는 3년전 위암 수술 후 정기 검진 중이었고 기타 다른 특 이할 만한 의과적 병력은 없었다. 진단을 위해 파노라마 방사선 사진 촬영 및 임상검사를 시행하였다(Fig. 2). 상 하악 모두 잔존치아가 고정성 보철물로 연결되어 있었고 이를 지대치로 하는 국소의치를 장착하고 있었다. 상악 우측 중절치 및 좌측 견치, 하악 좌측 견치는 탐침의 끝 이 치경부 치질 내로 들어가 2차 우식이 의심되었고, 상 악 좌측 측절치와 하악 측절치는 $6-7 \mathrm{~mm}$ 치주낭이 관 찰되었다. 하악 보철물은 1 도의 동요도를 보였으며, 방 사선 사진상 하악 지대치 모두에서 치주인대공간의 확장 이 관찰되고, 하악 우측 측절치와 견치 및 좌측 견치 치근 단에 방사선 투과상이 관찰되었다. 고정성 보철물을 모 두 제거하고 지대치를 재평가하였다. 잔존치 모두 2차 우 식으로 치경부 하방까지 치질이 소실되어 있었고, 전반적 으로 동요도가 관찰되어 국소의치의 지대치로 사용하기 에는 예후가 불량하다고 판단되었다. 따라서 잔존치아를 모두 발거하고 상악은 총의치, 하악은 유지력 증가와 경 제적인 면을 고려하여 2개의 임플란트를 식립하여 임플 란트 유지형 피개의치를 장착하도록 계획하였다.
치아 발거 후 바로 임시의치를 제작하였고 약 3 개월 후 임시의치를 이용하여 radiographic stent를 제작하였고, 이와 CT 사진을 참고해 골 상태가 비교적 양호한 하악 우측 견치, 좌측 견치를 임플란트 식립 위치로 선정하였 다. 1차 수술 시 어태치먼트의 유지력 소실을 최소화 하 기 위해 2 개의 임플란트를 서로 평행하게 심을 수 있도 록 surgical stent를 이용해 식립 부위를 표시하고 Parallel guide $\mathrm{KIT}^{\circledR}$ 사용하였다. KIT를 악궁 형태와 표시부위에 맞게 조정한 후, $\mathrm{KIT}^{\circledR}$ 에 Guide pin을 체결해 삽입 철거 로가 교합면과 수직하며 협설, 근원심으로 평행한지 확 인하고, 각각 직경 $4.0 \mathrm{~mm}$, 높이 $10 \mathrm{~mm}$ 임플란트 고정 체(US II OSSTEM, Seoul, Korea)를 식립하였다(Fig. 3). 하악 좌측 순측 부위는 치조골이 얇아 드릴링시에 얻은 골로 자가골 이식을 시행하였다.

3 개월의 치유기간을 가진 후 2 차 수술을 시행하였다. 공진 주파수 측정기(Osstell mentor, Osstell, Göteborg, Sweden) 검사상 임플란트의 안정성이 확인(하악 우측: 협측 74 , 설측 74 / 하악 좌측: 협측 77 , 설측 77 되어 보 철 수복을 진행하였다. 예비인상을 채득하여 진단모형

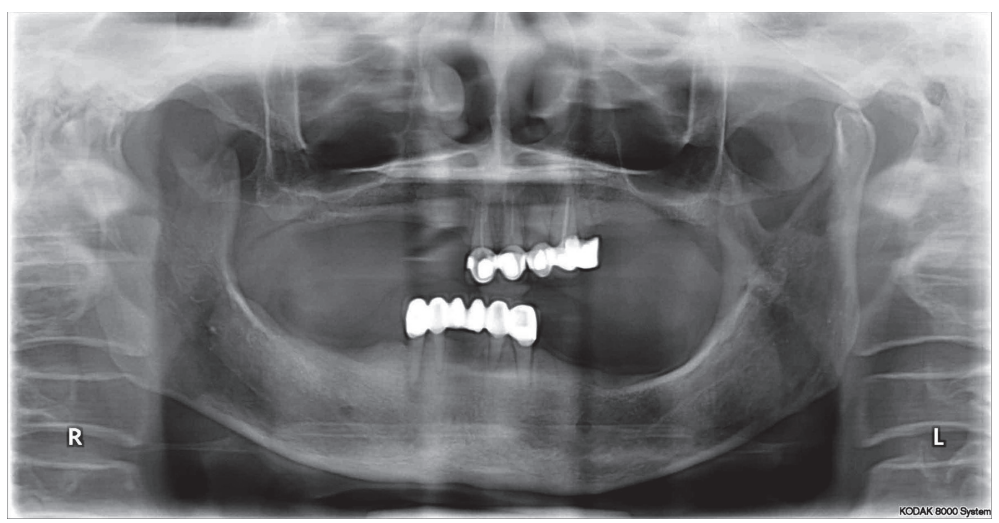

Fig. 2. Panoramic view at initial visit. 

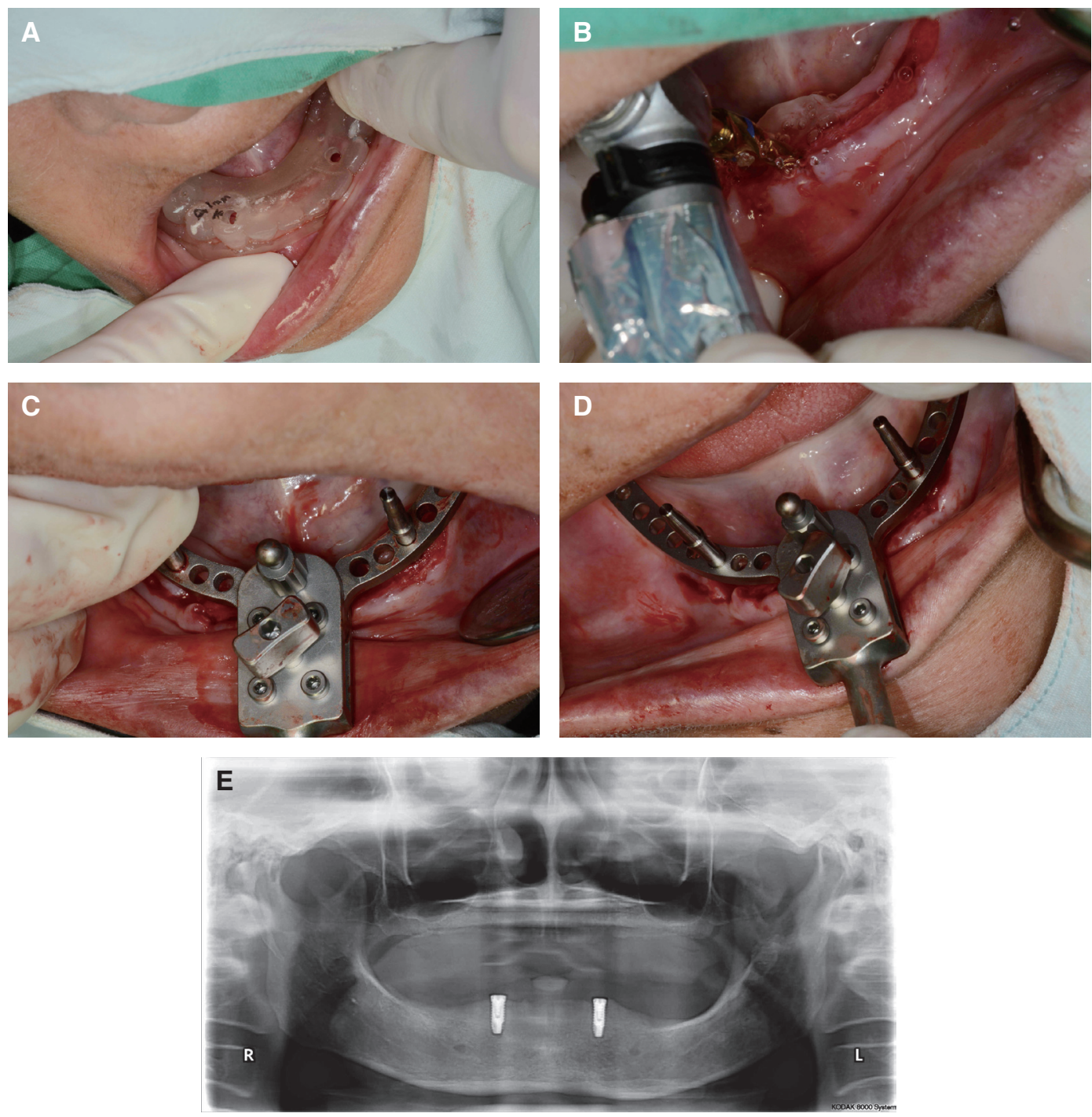

Fig. 3. (A) Marking planned position with surgical stent, (B, C) Positioning Parallel guide $K I T^{\circledR}$ at the center after adjusting to the arch form and the planned path, (D) Confirm position and path with guide pin on the Parallel guide $\mathrm{KIT}^{\circledR},(\mathrm{E})$ Panoramic view after $1^{\text {st }}$ surgery.

을 제작 한 후 최종 인상용 트레이를 제작하였다. 상하 악 모두 모델링 콤파운드를 이용해서 변연 형성을 하 였고, 상악은 폴리설파이드 인상재(Permlastic, Kerr Corporation, Romulus, USA)로, 하악의 경우 추가적으 로 임플란트 지대주에 인상용 코핑을 연결하고 실리콘 계열 인상재(EXADENTURE, GC, Tokyo, Japan)로 최 종 인상을 채득하였다(Fig. 4). 인상 채득 후 하악은 인상 용 코핑에 아날로그를 체결하여 주모형을 제작하였다. 최종인상 채득시 환자의 구강 내에서 인상용 코핑을 연 결하여 식립 위치와 방향을 확인했으며, 주모형 상에서 가이드 핀을 연결 하여 지대주가 계획된 위치에서 협설,
근원심적으로 평행하게 식립되어 있음을 다시 확인할 수 있었다(Fig. 5). 교합압에 의한 의치 파절을 방지하기 위 해 크롬-코발트 금속 구조물을 제작하였고 기록상과 교 합제를 제작하였다. 교합제를 구강 내에 시적 하여 동공 간선과 비익이주선을 기준으로 교합 평면을 설정한 후 중심위 기록 채득과 안궁 이전을 시행하였고(Fig. 6), 인 공 치아는 총의치의 안정을 고려하여 양측성 균형교합을 부여하여 배열하였다(Fig. 7).

완성된 의치는 약 2 주간 적응기간을 가진 후, 구내에서 어태치먼트를 장착하고 하악 최종의치에 메탈 하우징을 직접법으로 부착한 후 $3.0 \mathrm{lb}$ 유지력의 pink nylon을 연결 

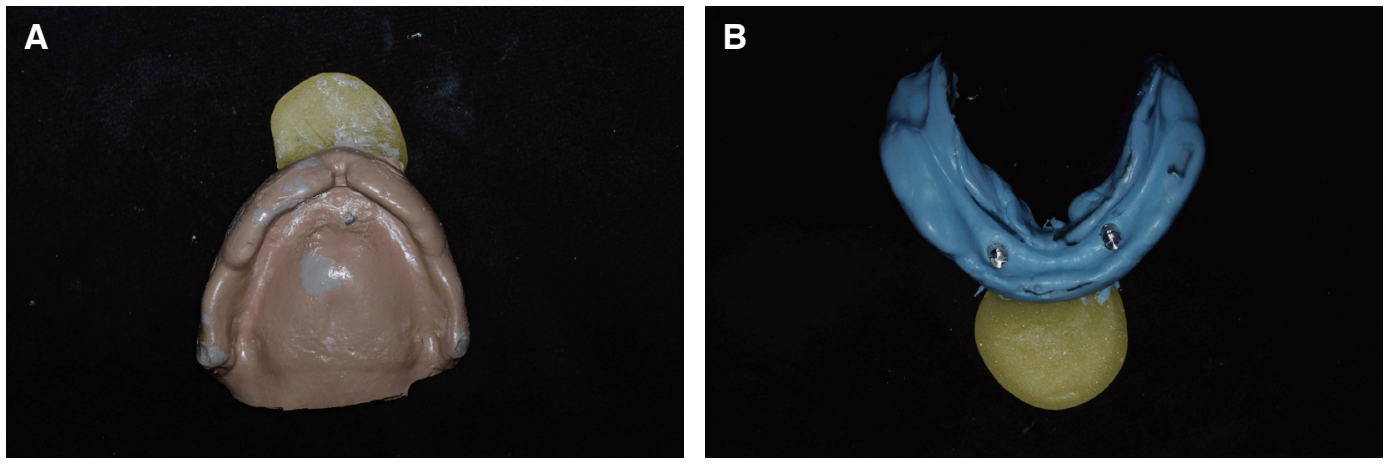

Fig. 4. Definitive impression for master cast. (A) Maxilla, (B) Mandible with impression coping.
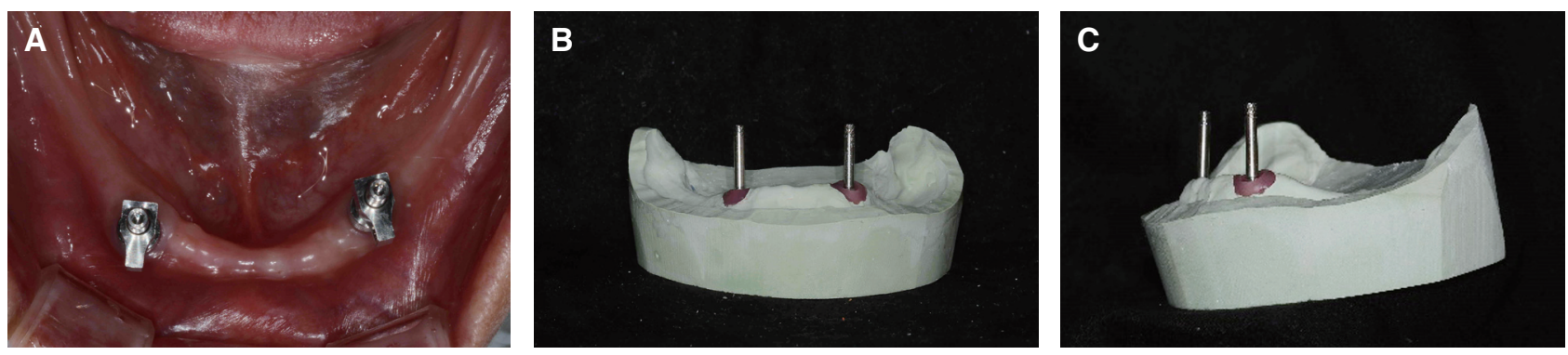

Fig. 5. Position and direction of implant. (A) Implant in the mouth. (B, C) Parallel direction of 2 implants on master cast. Coronal view (B), Sagittal view (C).

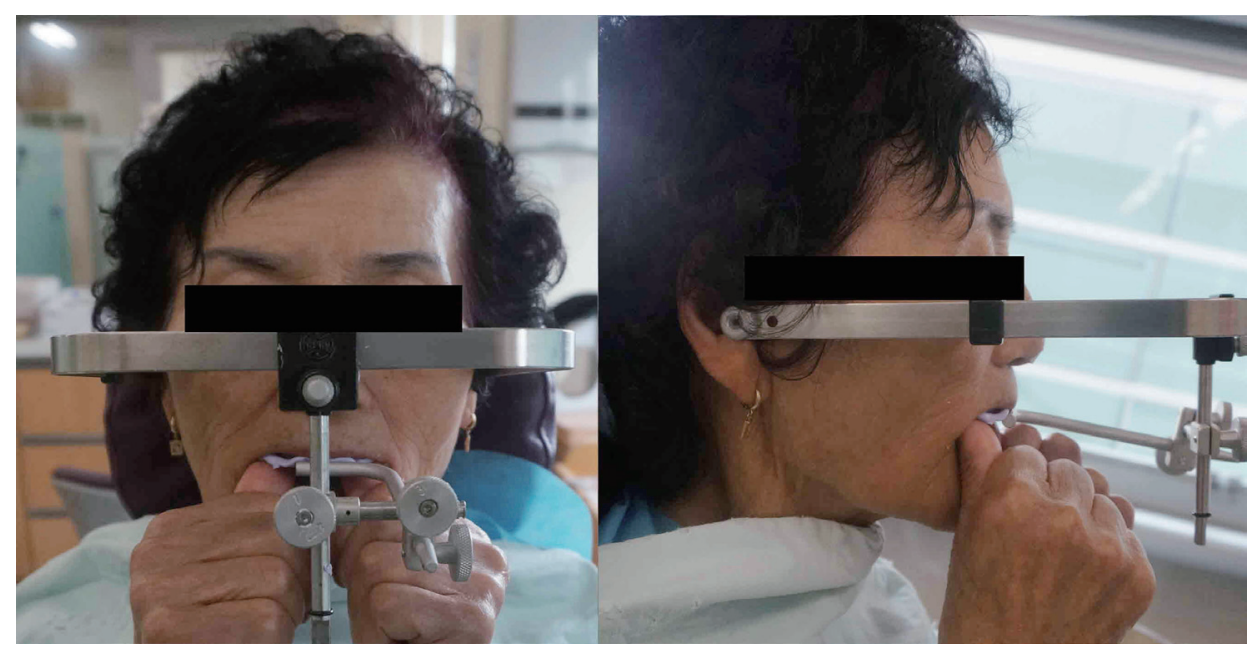

Fig. 6. Establishing occlusal plane and taking face-bow transfer.

하였다(Fig. 8). 장착 시 의치 사용 및 관리 방법과 구강위 생관리에 대해 교육한 후, 장착 24시간 후 재 내원하도록 하여 의치 조정을 시행하였으며, 1 개월, 3 개월, 6 개월 그 이후로는 매 6개월 마다 주기적인 검진을 하기로 계획하 고 내원의 필요성에 대하여 주지시켰다. 환자는 6개월 관
찰 시까지도 유지력의 큰 소실 없이 나일론 부품을 교체 하지 않고 만족스럽게 의치를 사용하였고, 기능적 심미 적으로 만족하였다. 임플란트의 동요도가 없었으며, 방 사선 사진상 임플란트 주변골의 흡수 또한 관찰되지 않 았다. 

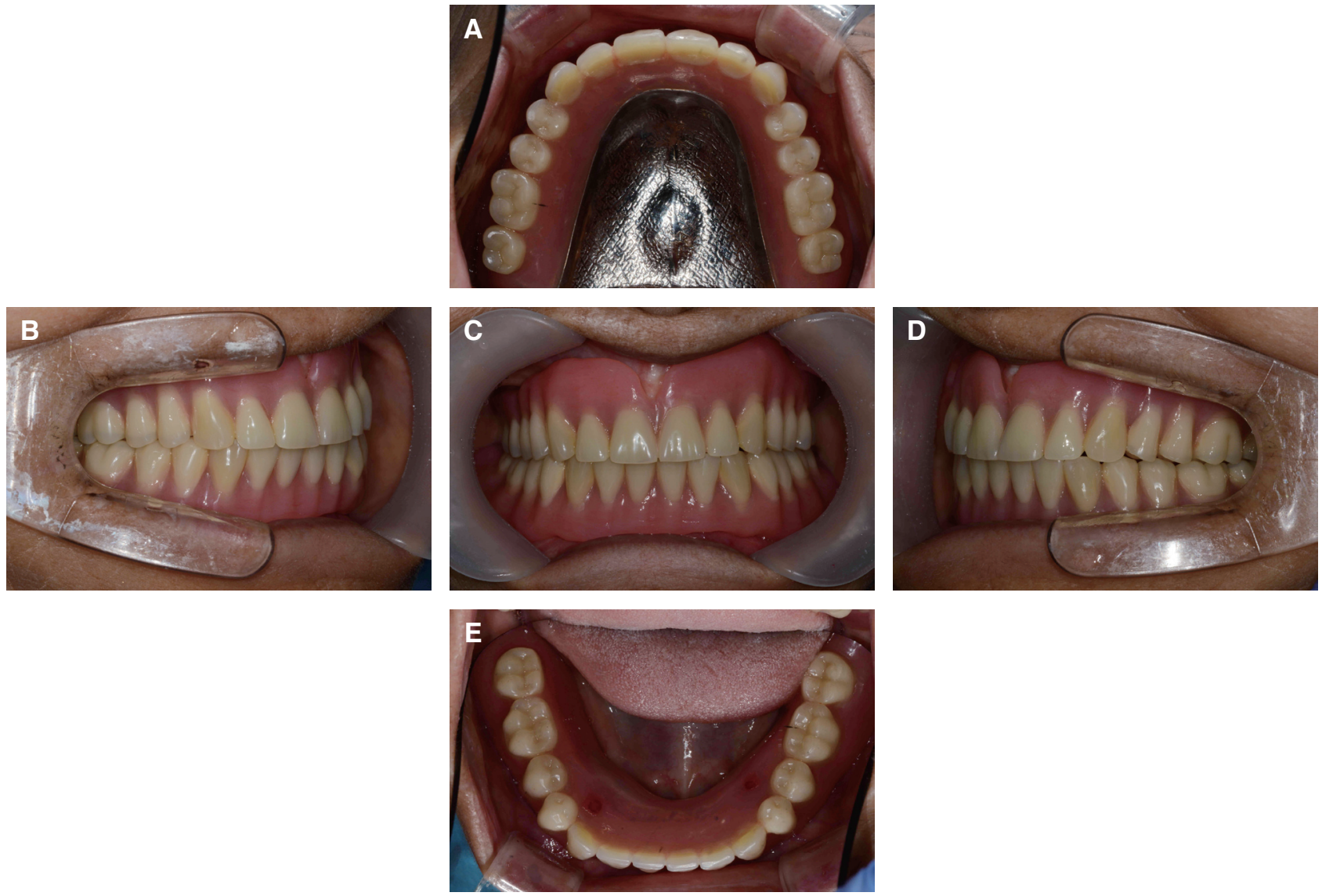

Fig. 7. Intraoral view of definitive dentures. All teeth contact evenly on centric relation.
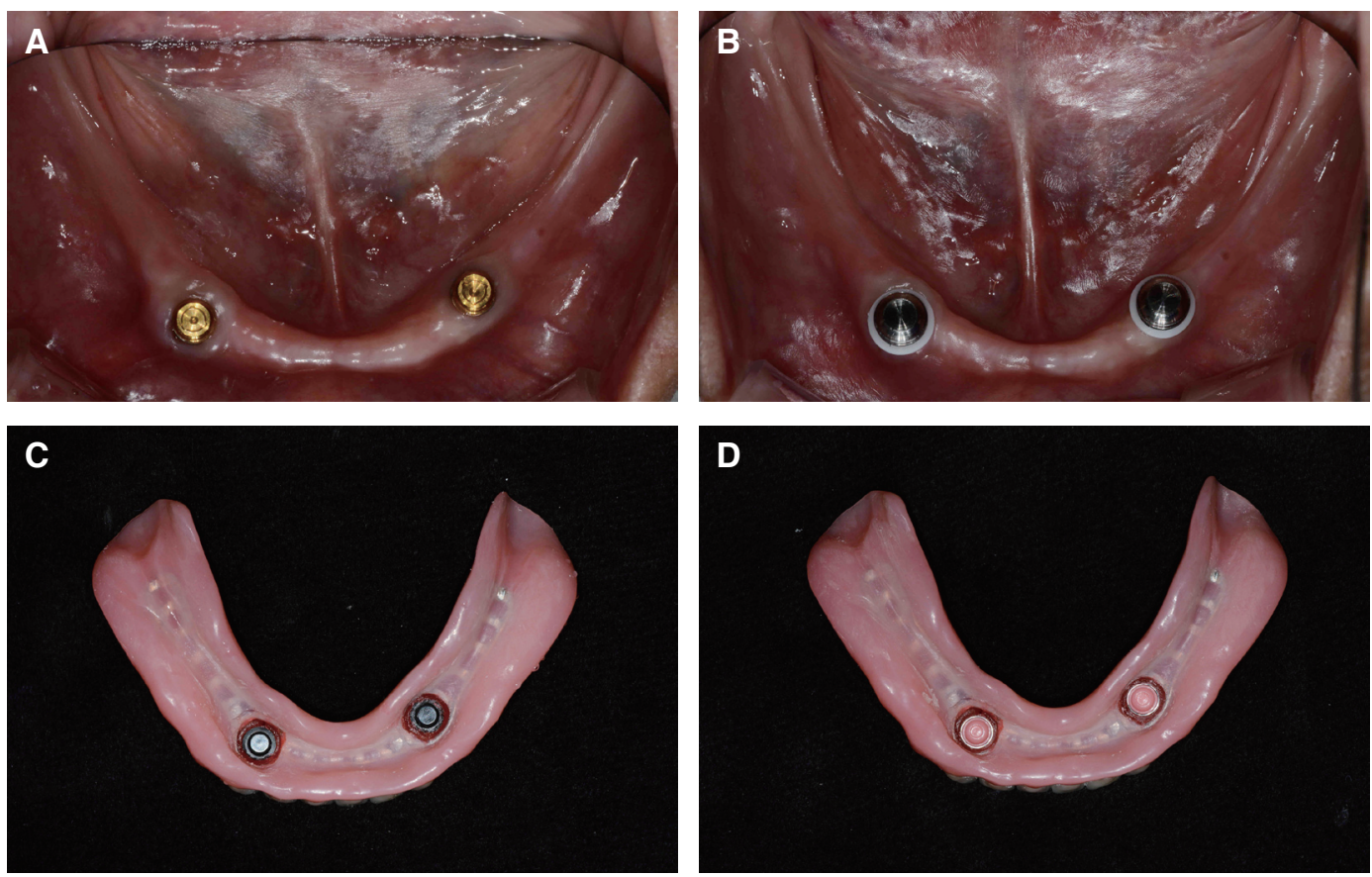

Fig. 8. Direct adaptation of Locator attachment. (A) Female part, (B) Metal housing, (C) Black male cap, (D) Pink male. 


\section{고찰}

상악 무치악의 경우 기존 총의치로도 충분한 지지와 유지를 얻을 수 있기 때문에 만족할 만한 결과를 얻을 수 있다. ${ }^{8}$ 반면 하악 무치악의 경우 충분한 지지와 유지를 얻 기가 힘들기 때문에 임플란트를 이용한 치료는 환자에게 많은 고통과 불편함을 경감시켜 줄 수 있다. 따라서 본 증례에서는 완전 무치악 환자에서 상악은 통상적인 총의 치, 하악은 2 개의 임플란트를 식립해 유지하는 피개의치 로 수복을 계획하였다.

임플란트 피개의치의 어태치먼트의 선택시 임플란트 식립 수, 위치, 식립 각도 등을 고려하여야 하는데 본 증 례의 환자는 악간 거리 및 기타 조건이 양호하여 2 개의 임플란트를 식립하여, 작은 수의 임플란트를 이용한 임 플란트 유지형 피개의치에 널리 사용되는 어태치먼트인 Locator 어태치먼트로 수복하기로 했다. Locator 어태 치먼트는 그간 국소의치나 피개의치에 널리 사용되어 왔 던 O-ring과 Nylon Cap의 조합으로 이중유지를 가지며, 수직적으로 적은 공간을 필요로 하며, 나일론 부품의 교 체에 따른 유지력 조절이 용이한 장점이 있다. 하지만 기 능 시 Locator는 임플란트간 각도가 클수록 bar나 ball 에 비해 유지력 감소가 크며, 특히 협설간 각도차이가 클 수록 그 영향이 더욱 크다. ${ }^{9}$ 따라서 임플란트 식립시 정면 과 측면 모두에서 평행하게 식립하도록 주의해야 한다. Parallel guide $\mathrm{KIT}^{\circledR}$ 는 중심을 기준으로 폭을 늘이거나 줄일 수 있고, 이 중심점을 고정할 때 교합면과 이루는 각 도를 맞출 수 있으며, KIT에 형성돼 있는 여러 홀 중 위 치를 선택하여 임플란트간 식립 간격을 조절할 수가 있 다. 계획한 위치와 방향으로 KIT를 위치시키고 미끌림이 방지되는 twist dill로 피질골을 드릴링해 식립을 하면 임 플란트간에 평행하게 식립 하기가 용이하다.

임플란트 피개의치는 치료 이후의 적절한 유지 관리 가 장기적으로 봤을 때 실질적인 성공의 요인이다. 따라 서 임플란트의 기계적, 생물학적 실패를 막기 위해 임플 란트 지대주에 가해지는 힘의 조절과 구강위생관리가 필 수적이다. 본 증례는 Parallel guide $\mathrm{KIT}^{\circledR}$ 를 이용해 임플 란트를 계획된 위치에, 의치의 삽입 철거로와 평행하게 식립하여 Locator 어태치먼트의 가장 흔한 유지관리 합 병증인 나일론 부품의 유지력 상실을 최소화하고자 하였 다. 정기적인 검진과 경과관찰을 통해 치조골 흡수 및 조 직 변형 시 적절한 재이장과 교합조정과 부품의 교체가 필요할 것이다.

\section{결론}

본 증례는 무치악 환자에서 하악에 2 개의 임플란트를 Parallel guide $\mathrm{KIT}^{\circledR}$ 를 이용해 협설, 근원심적으로 평행 하게 심고, Locator 어태치먼트를 이용한 임플란트 피개 의치로 수복하여 6 개월 정기 검사 기간 동안 유지력의 소 실 없이 만족할 만한 결과를 얻었기에 보고하는 바이다.

하악골이 많이 흡수된 환자에게 2개의 임플란트를 하 악 전방부위에 식립한 후 Locator 어태치먼트를 이용한 임플란트 유지 피개의치를 적용하는 것은 비용적인 측면 에서도 상당히 유리하며, 최소의 침습적인 수술이 가능 하기에 고령의 환자에게 적극적으로 추천된다. 그러나 동시에 Locator 어태치먼트는 기능 하에서 유지력이 빠 르게 감소하는 특징이 있어 나일론 부품의 교체율이 높 은 편이므로, 이를 최소화 하기 위해 가급적 임플란트를 평행하게 식립하려는 노력이 필요하다. ${ }^{6,79}$

\section{ORCID}

Hyeran Kim http://ordid.org/0000-0002-2992-5985 Jun-Yub Kim http://ordid.org/0000-0002-6047-9733 Hong-So Yang http://orcid.org/0000-0002-9138-4817 Sang-Won Park http://orcid.org/0000-0002-9376-9104 Hyun-Pil Lim http://orcid.org/0000-0001-5586-1404 Kwi-Dug Yun http://orcid.org/0000-0002-2965-3967 Chan-Park http://orcid.org/0000-0001-5729-5127

Jin-Ho Shin http://orcid.org/0000-0003-2027-0614

\section{References}

1. Feine JS, Carlsson GE, Awad MA, Chehade A, Duncan WJ, Gizani S, Head T, Lund JP, MacEntee M, Mericske-Stern R, Mojon P, Morais J, Naert I, Payne AG, Penrod J, Stoker GT, Tawse-Smith A, Taylor TD, Thomason JM, Thomson WM, Wismeijer D. The McGill consensus statement on overdentures. Mandibular two-implant overdentures as first choice standart of care for edentulous patient. Montreal, Quebec, May 24-25, 2002. Int J Oral Maxillofac Implants 2002;17:601-2.

2. Misch CE. Dental implant prosthetics. 2nd ed. Beijing; ELSEVIER; 2015. p. 573-97.

3. Sadowsky SJ. Treatment considerations for maxillary 
implant overdentures: a systemic review. J Prosthet Dent 2007;97:340-8.

4. Trakas T, Michalakis K, Kang K, Hirayama H. Attachment systems for implant retained overdentures: a literature review. Implant Dent 2006;15:24-34.

5. Schneider AL, Kurtzman GM. Bar overdentures utilizing the Locator attachment. Gen Dent 2001; 49:210-4.

6. Abi Nader S, de Souza RF, Fortin D, De Koninck L, Fromentin O, Albuquerque Junior RF. Effect of simulated masticatory loading on the retention of stud attachments for implant overdentures. J Oral Rehabil 2011;38:157-64.
7. Uludag B, Polat S. Retention characteristics of different attachment systems of mandibular overdentures retained by two or three implants. Int J Oral Maxillofac Implants 2012;27:1509-13.

8. Kim SW. Implant overdenture. Seoul; Myoung Mun Publishing Company; 2007.

9. Jabbour Z, Fromentin O, Lassauzay C, Abi Nader S, Correa JA, Feine J, de Albuquerque Junior RF. Effect of implant angulation on attachment retention in mandibular two-implant overdentures: a clinical study. Clin Implant Dent Relat Res 2014; $16: 565-71$ 


\section{하악 무치악 환자에서 Parallel guide $\mathrm{KIT}^{\circledR}$ 를 이용한 임플란트 식립 및 Locator 어태치먼트를 이용한 임플란트 피개의치 수복증례}

\section{김혜란, 김준엽, 양홍서, 박상원*, 임현필, 윤귀덕, 박 찬, 신진호}

전남대학교 치의학전문대학원 보철학교실

무치악 환자를 수복할 때 임플란트 피개의치를 이용한 치료법은 전통적인 총의치의 문제점인 저작시 동통, 의치의 부족 한 유지와 안정을 포함하는 기능저하 문제 등을 해결할 수 있는 방법이다. Locator ${ }^{\circledR}$ (Zest Anchors LLC, Espandido, USA) 어태치먼트는 임플란트 피개의치에 사용되는 어태치먼트 중 수직적으로 필요한 공간이 가장 적고, 나일론 부품에 따라 유지력 조절이 용이하다. 하지만 Ball이나 Bar에 비해 기능시 부품의 마모로 유지력이 빠르게 감소하는 특징이 있어 가급적 임플란트 간 각도가 최소가 되도록 식립하려는 노력이 필요하다.

(구강회복응용과학지 2017;33(1):55-62)

주요어: Locator; 어태치먼트; 임플란트 피개의치; 평행 